\title{
Numerical modelling of past retreat and future evolution of Chhota Shigri glacier in Western Indian Himalaya
}

\author{
Prateek GANTAYAT, ${ }^{1}$ Anil V. KULKARNI, ${ }^{1}$ J. SRINIVASAN, ${ }^{1}$ Maurice J SCHMEITS ${ }^{2}$ \\ ${ }^{1}$ Divecha Centre for Climate Change, Indian Institute of Science, Bangalore 560012, India \\ E-mail: gantayat.prateek@ymail.com \\ ${ }^{2}$ Koninklijk Nederlands Meteorologisch Instituut, De Bilt, Netherlands
}

\begin{abstract}
The history of glacier length fluctuations serves as a reliable indicator of the past climate. In this paper, a numerical flowline model has been used to study the relationship between length variations of Chhota Shigri glacier and local climate since 1876. The simulated front positions of Chhota Shigri glacier are in agreement with those observed. After a successful simulation of the past retreat, the model was also used to predict future evolution of the glacier for the next 100 years under different climatic scenarios. These simulations indicate that the Chhota Shigri glacier may lose $\sim 90 \%$ of its present volume by 2100 if the local temperature increases by $2.4 \mathrm{~K}$, and for a temperature rise of $5.5 \mathrm{~K}$, the glacier loses almost all its volume.
\end{abstract}

Keywords: climate change, glacier flow, glacier mass balance, ice thickness measurements, remote sensing

\section{INTRODUCTION}

With an ice coverage of $40775 \mathrm{~km}^{2}$, the HimalayaKarakoram region has one of the largest glacier coverages outside the Polar regions (Bolch and others, 2012; Frey and others, 2014). Livelihood of a sizeable part of the population is dependent on glacier fed rivers that originate from The Himalaya. Recent investigations suggest that the majority of Himalayan glaciers are retreating due to climate change (Kulkarni and others, 2011; Kulkarni and Karyakarte, 2014). Therefore, in order to assess their sustainability as well as future evolution, it is important to explore the relationship between glacier front fluctuations and climate change. A record of glacier mass balance is an important tool for such studies. However, owing to harsh climatic conditions and difficult terrain in this region, mass-balance investigations have been difficult and also are limited to few selected glaciers (Berthier and others, 2007). Apart from mass balance, topographic maps and glacier retreat records do give some insight into changes in glacier length and surface area, but the state of balance or imbalance with respect to local climate cannot be inferred (Oerlemans, 2001). In such a situation, numerical modelling of glacier flow can be a feasible alternative to in-situ measurements. Numerical flowline modelling has been successfully used for estimating past retreat as well as future evolution of glaciers located in different climatic conditions, around the world (Stroeven, 1996; Oerlemans, 1997; Schmeits and Oerlemans, 1997; De Smedt and Pattyn, 2003). Unfortunately, such flowline studies have not been carried out in the Indian Himalaya.

In this paper, we use a numerical flowline model to simulate the past retreat and future evolution of Chhota Shigri glacier, located in the Indian Himalaya. The glacier was considered for our analyses, mainly because it has been chosen as the benchmark glacier in the western Himalaya; is easily accessible; and most importantly, it is located in an area influenced by Indian monsoon in summer and mid-latitude westerlies in winter (Wagnon and others, 2007). A wide accumulation area and a relatively narrow ablation zone renders the glacier sensitive to climate change. Also, among other Himalayan glaciers Chhota Shigri has one of the longest records of continuous in-situ mass-balance estimates spanning 2002-14 (Azam and others, 2016).

\section{STUDY AREA}

The Chhota Shigri glacier is located on the Chandra river basin in Himachal Pradesh (Fig. 1). The valley glacier is oriented north-south in ablation zone, and the accumulation zone is differently oriented. The glacier geometry is complex with three tributaries. The ice flow in the main trunk is mainly due to ice from the tributary (B) and the main trunk (A) (Wagnon and others, 2007). The ice flow in the accumulation zone has contribution from four small cirques namely b1, b2, b3 and b4 (Fig. 1). Continuous mass-balance observations have been carried out on this glacier since 2002 by the glaciological method (Wagnon and others, 2007; Azam and others, 2016). The observed specific mass balance averaged over every altitudinal band of $50 \mathrm{~m}$ is shown as a function of altitude in Figure 2. The specific mass-balance ranges from 1.5 to $-2.5 \mathrm{~m}$ w.e. $\mathrm{a}^{-1}$. Below an altitude of $\sim 4400 \mathrm{~m}$, the specific mass balance increases due to the presence of debris cover (Azam and others, 2016). Further details regarding specific mass balance of Chhota Shigri glacier can be found in Wagnon and others (2007); Azam and others (2016). In addition, point surface velocity and ice thickness observations are available for the year 2004/05 (Tiwari and others, 2014). The snout position has been monitored from 1962 onwards (Ramanathan, 2011). Since 1995, the glacier has been constantly retreating. From 1972 till 2009, the glacier has retreated by $800-850 \mathrm{~m}$ (Kulkarni and others, 2007; Shruti, 2008). The other characteristics of the glacier are listed in Table 1.

\section{METHODOLOGY}

\section{Model used}

The model used in this study is solely based on mass conservation, and it describes ice flow along the central flowline, 


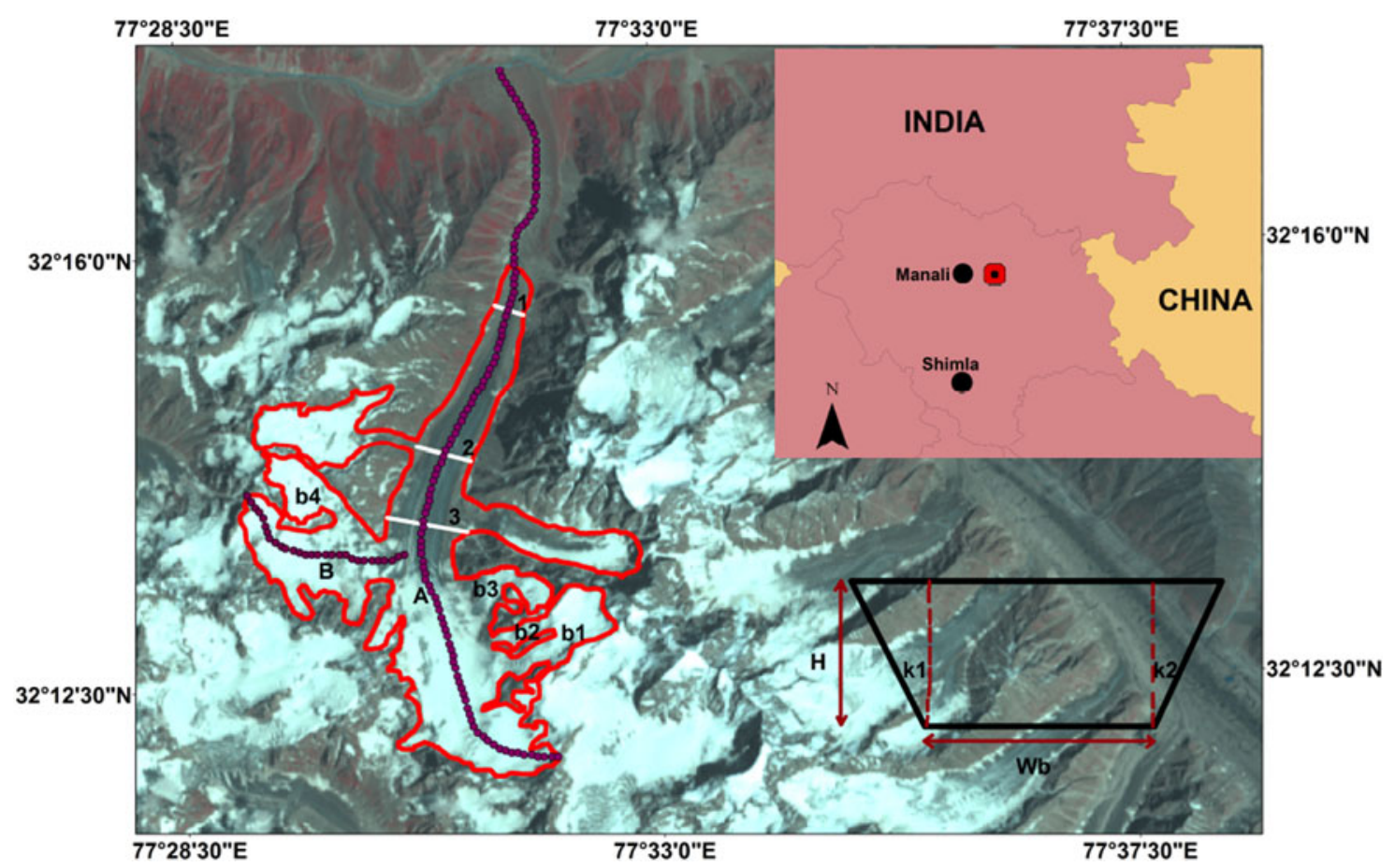

Fig. 1. Map of Chhota Shigri glacier showing the different tributaries, cirques considered for the analyses. A, B represents the main stream and the tributary, respectively. b1, b2, b3, b4 represent the cirques that contribute ice to both A and B. The cross sections where GPR measurements were available have been labelled as 1,2 and 3. In the inset map of India, the location of Chhota Shigri glacier is shown as a red dot. The flowlines used in the analyses are shown as dotted red lines. The cross section is parameterized as a trapezium of base width $w_{\mathrm{b}}$, height $\mathrm{H} . \mathrm{k} 1, \mathrm{k} 2$ represent the orientation of the valley walls. $\lambda=(\tan (\mathrm{k} 1)+\tan (\mathrm{k} 2))$.

assuming that a glacier cross section can be approximated as a trapezium. A detailed description of the model can be inferred from Oerlemans (1997). For a given glacier cross section, mass conservation can be stated as

$$
\frac{\partial H}{\partial t}=\frac{-1}{w_{\mathrm{b}}+\lambda H} \frac{\partial}{\partial x}\left(\left(w_{\mathrm{b}}+0.5 \lambda H\right) U H\right)+B
$$

where $H$ is local ice thickness $(m), w_{\mathrm{b}}$ the width of cross-section's base $(\mathrm{m}), \lambda$ parametrizes the orientation of the side walls (Fig. 1$), B$ is the specific mass balance (m w.e. $\left.\mathrm{a}^{-1}\right), t$ the time and $U$ is vertically averaged mean cross-sectional velocity $\left(\mathrm{m} \mathrm{a}^{-1}\right)$. Since, the model is 1-D and neglects transverse gradients of velocity, vertically averaged and mean cross-sectional velocity are the same. $U$ can be further expressed as

$$
U=f_{k}^{3}\left(f_{1} Y H^{4}\left(\frac{\partial h}{\partial x}\right)^{2} \frac{\partial h}{\partial x}+f_{2} Y H^{2}\left(\frac{\partial h}{\partial x}\right)^{2} \frac{\partial h}{\partial x}\right)
$$

where $Y=(\rho g)^{3}, \rho$ is the ice density and is assumed to have a constant value of $900 \mathrm{~kg} \mathrm{~m}^{-3}, g=9.8 \mathrm{~m} \mathrm{~s}^{-2}, f_{1}$ and $f_{2}$ represent the deformation and sliding flow parameters and are assumed to be $1.9 \times 10^{-24} \mathrm{~Pa}^{-3} \mathrm{~s}^{-1}$ and $5.7 \times 10^{-20}$ $\mathrm{Pa}^{-3} \mathrm{~m}^{2} \mathrm{~s}^{-1}$, respectively (Budd and others, 1979), $f_{\mathrm{k}}$ is a correction factor that parametrizes the effects of lateral and longitudinal drag (Nye, 1965; Adhikari and Marshall, 2011,
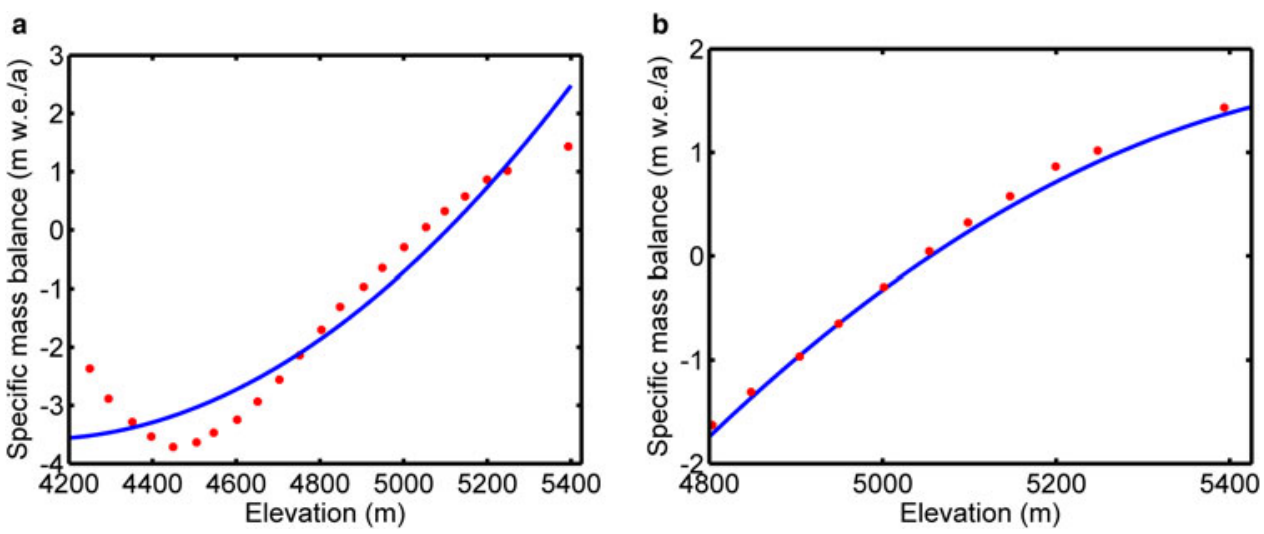

Fig. 2. (a) Mass balance of main stream of Chhota Shigri glacier for the period 2002-14 (Azam and others, 2016). Red dots represent the observed data and blue represents the quadratic polynomial that has been used as a fit to the mass-balance curve $\left(R^{2}=0.89\right.$ ). (b) Mass balance of tributary of the glacier. It is estimated by correcting the mass-balance profile in '(a)' for altitude. Red dots represent the observed data and blue represents the quadratic polynomial that has been used as a fit to the mass-balance curve $\left(R^{2}=0.98\right)$. The polynomial fits are used to force the model. 
Table 1. Chhota Shigri glacier mass-balance information

\begin{tabular}{llll}
\hline Glacier name & $\begin{array}{l}\text { Length (2009) } \\
\mathrm{Km}\end{array}$ & $\begin{array}{l}\text { ELA in } \\
2009\end{array}$ & $\begin{array}{l}\text { Years of mass-balance } \\
\text { available }\end{array}$ \\
\hline Chhota Shigri & 9 & $4925 \mathrm{~m}$ & $2002-14$
\end{tabular}

2012). However, lateral and longitudinal stresses seldom have an impact over decadal or century scale retreat as compared with mass balance (Oerlemans, 2001). In fact on repeating the analyses with $f_{k}=1$, the results were not different from those that were obtained by assuming $f_{k}$ to be a constant but not equal to one. This is probably because as compared with other model uncertainties and the rather simplistic treatment of ice flow, the effect of the correction factor is probably insignificant (Oerlemans, 2001); $h$ is surface elevation $(\mathrm{m})$, expressed as

$$
h=h_{\mathrm{b}}+H,
$$

where $h_{\mathrm{b}}$ is bed elevation $(\mathrm{m})$. The model equation used in our analyses can be obtained by combining Eqns (1) and (2):

$$
\frac{\partial H}{\partial t}=\frac{-1}{w_{\mathrm{b}}+\lambda H} \frac{\partial}{\partial x}\left(D \frac{\partial h}{\partial x}\right)+B
$$

where $D$ is defined as diffusivity $\left(\mathrm{m}^{2} \mathrm{a}^{-1}\right)$ and is expressed as:

$$
D=\left(w_{\mathrm{b}}+0.5 \lambda H\right) f_{k}^{3}\left(f_{1} Y H^{5}\left(\frac{\partial h}{\partial x}\right)^{2}+f_{2} Y H^{3}\left(\frac{\partial h}{\partial x}\right)^{2}\right) \text {, }
$$

Specific mass-balance $B$ can be further expressed as (Oerlemans, 2001)

$$
B(h, t)=B_{\text {ref }}(h)+b(t)+\delta B,
$$

where $B_{\text {ref }}$ is the reference specific mass-balance profile and is solely a function of $h$. $B_{\text {ref }}$ is obtained from glaciological records; $b(t)$ represents the balance perturbations derived from proxies such as temperature, precipitation, tree rings etc. $b(t)$ is purely a function of time and is applied irrespective of altitude; $\delta B$ is a constant whose value is chosen such that the model produces equilibrium states that are very close to current glacier stands. $\delta B$ is also applied irrespective of altitude.

\section{Estimation of bed topography}

Local ice thickness $(H)$ is estimated using the relationship between surface velocity, slope and ice thickness (Paterson, 2010; Gantayat and others, 2014)

$$
u_{\mathrm{s}}=u_{\mathrm{b}}+\frac{2 A}{n+1}(f \rho g H \sin (\alpha))^{n},
$$

where $u_{\mathrm{s}}$ and $u_{\mathrm{b}}$ represent the surface and basal velocities, respectively; $u_{\mathrm{b}}$ is assumed to be $25 \%$ of $u_{\mathrm{s}}, n=3$ is Glen's constant (Glen, 1955), $f$ is a correction factor that parametrizes lateral and longitudinal stress and it can be tuned using published estimates of observed ice thickness (Nye, 1965; Adhikari and Marshall, 2011, 2012). For Chhota Shigri glacier, $f$ was tuned at three cross sections namely 1 , 2, 3 (Fig. 1) where observed ice thickness estimates were available (Azam and others, 2012), $A$ is Creep parameter $=$ $3.2 \times 10^{-24} \mathrm{~Pa}-3 \mathrm{~s}^{-1}$ and $\sin (\alpha)$ is the mean surface slope of every glacier area located between two altitudinal bands having $100 \mathrm{~m}$ difference in their respective elevations.

In this paper, for estimating $H$ Eqn (7) was first solved along discrete points of manually digitized branchlines (e.g. Linsbauer and others, 2012), and the resulting ice thickness was spatially interpolated assuming zero ice thickness at the glacier margin. For interpolation, ANUDEM (Australian National University DEM) was used (Hutchinson, 1989). While digitizing individual branchlines, the following steps were taken: (a) a lateral spacing of 200-220 m was maintained between adjacent lines; (b) a minimum distance of 100-150 m was maintained between the branchlines and glacier margin; (c) the branchlines from a tributary were made to gradually merge with the branchlines from the main stream. Bed elevation was then estimated by subtracting the resulting ice thickness map from the local DEM. Lastly, the bed topography was smoothed using a 3-by-3 filter to remove small undulations. Details regarding the algorithm can be found in Farinotti and others (2017).

The initial bed elevation profile $\left(h_{\mathrm{b}}\right)$ and initial base width $\left(w_{\mathrm{b}}\right)$ were estimated from the bed topography estimated above. For estimating the value of $f_{k}$ (see Eqn (2)), values of $f$ across cross sections 1,2 and 3 (Fig. 1) were estimated by tuning modelled ice thickness in Eqn (7) with GPR estimates. The value of $f_{k}$ was assumed to be the mean of the above estimated values of $f$.

\section{NUMERICAL IMPLEMENTATION}

Equation (4) was solved numerically along the two central flowlines with a horizontal grid spacing of $100 \mathrm{~m}$ (Fig. 1). It was observed that two flowlines would be sufficient to parametrize the ice flow in the Chhota Shigri glacier complex (Fig. 1). A forward explicit finite-difference scheme was used for the analyses.

\section{Addition of ice from cirques to main stream}

The accumulation zone of the main stream is partly fed by 3 cirques and the accumulation zone of the tributary by 1 cirque (Fig. 1). Details regarding the bed geometry of the cirques were not known and due to their steep slopes, shallow ice approximation will not be applicable. Therefore, it was decided to estimate only the mass flux from the cirques at every time step. To do so the scheme suggested by Schmeits and Oerlemans (1997) was used. First, the ice volume of the cirque at time $t$ is calculated according to

$$
\frac{\mathrm{d} v}{\mathrm{~d} t}=\sum_{i} \mathrm{a}\left(h_{i}\right) b\left(h_{i}\right)-\frac{v}{t^{*}}
$$

where $v$ is the volume of the cirque at time $t$. Here $a(h i)$ and $b\left(h_{\mathrm{i}}\right)$ are the area and the mass balance of the elevation interval (100 $\mathrm{m}$ in this study) respectively, centred around $h_{\mathrm{i}} ; i$ is the number of the elevation band. The first term on the right represents the mass gain and the second term represents volume lost to the main stream/tributary. $t^{*}$ is defined as the characteristic timescale and has been introduced to take into account owing to the fact that mass flux due to ice flow from the cirques to the main stream/tributary may take several 
years. $t^{*}$ is defined as

$$
t^{*}=\frac{L^{*}}{U^{*}}
$$

where $L^{*}$ and $U^{*}$ are defined as the characteristic length scale and velocity, respectively. $L^{*}$ is assumed to be half the cirque's length. $U^{*}$ depends on the mean ice thickness and mean surface slope of the basin. Therefore, $t^{*}$ varies from cirque to cirque. A list of $t^{*}$ for the 4 cirques has been given in Table 2. Therefore, at every time step $\Delta t$, an amount of ice volume equal to $\left(\left(v / t^{*}\right) \Delta t\right)$ is added from the cirques. The ice volume is then equally distributed over a certain number of grid points on the main stream/tributary (for numerical stability). This is then converted to respective ice thickness and is added at the respective gridpoints.

\section{Addition of ice from tributary to main stream}

The ice flux from the tributary to the main stream is estimated (Schmeits and Oerlemans, 1997) as follows:

$$
F=U(w H)
$$

At every time step $\Delta t$, the flux between the last two gridpoints of the tributary was estimated and was assumed to be a good approximation of the ice flux that is added from the tributary to the main stream. Ice flux times $\Delta t$ gives the volume that is added to the main stream. If the surface elevation of the tributary was more than that of the main stream, ice volume was added to the main stream. The volume is equally distributed across the nearest three grid points on the main stream (for numerical stability). The distributed volume is then converted into respective ice thickness, which is added to the main stream at the corresponding gridpoints.

\section{Estimation of $\Delta t$ (time step)}

For solving Eqn (4) for a glacier with unit width, a critical time step of 0.01 a was estimated using the CFL condition (Smith, 1978):

$$
\Delta t \leq(\Delta x)^{2} / 4 D_{\mathrm{a}}
$$

where $\Delta x$ is the horizontal grid spacing and $D_{\mathrm{a}}$ is the average diffusivity. Finally, for the simulation of retreat of Chhota Shigri glacier (accounting for the variable width), a step of 0.001 a was chosen because lowering the time step further, did not affect the model results.

\section{DATA USED AND MODEL INITIALIZATION}

For solving Eqn (4), we need (a) two central flowlines representing ice flow along main trunk and tributary, (b) surface

Table 2. Estimated characteristic timescales of the four cirques

\begin{tabular}{lllll}
\hline Cirque name & $\begin{array}{l}H_{\text {mean }} \\
M\end{array}$ & $\begin{array}{l}L\left(L^{*}=L / 2\right) \\
\text { b1 }\end{array}$ & $\begin{array}{l}u^{*} \\
\mathrm{~m} \mathrm{a}^{-1}\end{array}$ & $\begin{array}{l}t^{*}=L^{*} / u^{*} \\
\mathrm{a}\end{array}$ \\
\hline b2 & 33 & 1721 & 33 & 26 \\
b3 & 23 & 816 & 29 & 14 \\
b4 & 24 & 1035 & 44 & 12 \\
& 35 & 1247 & 14 & 46 \\
\hline
\end{tabular}

elevation profile along the flowlines, (c) initial bed elevation profile along the flowlines, (d) initial estimate of $w_{\mathrm{b}}$ and $\lambda,(\mathrm{e})$ reference mass-balance profiles, and $(f)$ proxy data for simulating retreat.

The two central flowlines were manually digitized such that they were orthogonal to the surface elevation contours (Fig. 1). Surface elevation values required for the model were taken from the local ASTER DEM (downloaded freely from earthexplorer.usgs.gov/). To remove spatial bias, it was co-registered with one of the Landsat 8 images and was then smoothened using a 3-by-3 filter. The DEM obtained now was used in further analyses. The surface elevation values required for Eqn (1) were extracted from DEM using ArcMap 9.2. For estimating initial bed topography, ice thickness was estimated from surface velocities generated using 2 Landsat-8 PAN scenes (Table 3). Surface velocities were estimated using sub-pixel correlation (e.g. Leprince and others, 2007; Gantayat and others, 2014). To tune the ice thickness model, we have published estimates of observed ice thickness across three cross profiles. These observations were taken during October 2009 (Azam and others, 2012). While doing so we assumed that over a period of 5-6 years, the ice thickness and surface elevation values will not change drastically ( $>$ RMS error of the DEM). Mass-balance profile (2002-14) for the main stream was inferred from Azam and others (2016). The balance profile of the tributary was derived by correcting the main stream's mass-balance profile for altitude (Fig. 2). $B_{\text {ref }}$ for both main stream and tributary was estimated by fitting a second-order polynomial through the data points (Figs 2a, b). For simulating retreat, annual mean temperatures and annual and seasonal accumulated precipitation (since, 1876) from the meteorological observatory at Shimla has been taken. The observatory is located at $31.1048^{\circ} \mathrm{N}$, $77.1734^{\circ} \mathrm{E}$, at an elevation of $2202 \mathrm{~m}$ and is maintained by the Indian Meteorological Department (IMD) (Fig. 1).

Using the above data, zero ice volume as the initial condition, and the flow parameters $\left(f_{1}\right.$ and $\left.f_{2}\right)$ specified above, the model (Eqn (4)) was run by setting $\delta B=0 . \delta B$ was then adjusted in order to simulate a steady-state glacier having the same length as that of Chhota Shigri in $2009(9 \mathrm{~km})$ (Wagnon and others, 2007). The flow parameters and the bed geometry were adjusted till the RMS difference between simulated and observed surface elevation in 2009 was minimum as well as until the area-altitude distribution of the simulated glacier matched with that derived from the DEM within acceptable limits $\left(<0.1 \mathrm{~km}^{2}\right.$ in our case) (e.g. Oerlemans, 2001). While adjusting the bed, care was taken to ensure that the geometry of the cross sections where ice thickness was modelled using GPR measurements was not altered (Fig. 1). While adjusting the flow parameters, due to lack of field estimates of $f_{1}$ and $f_{2}$, it was decided to keep the ratio $f_{1}: f_{2}$ constant at all times. It was observed that along with the above specified modifications, when $\delta B$ was assigned a value of 0.03 and $0.06 \mathrm{~m}$ w.e. $\mathrm{a}^{-1}$ for $A$ and $B$, a steady-state glacier with length corresponding to that in 2009 was simulated. Such an approach for tuning flow parameters and bed geometry has been used in the past (e.g. Adhikari and Huybrechts, 2009). Instead of tuning the flow and bed parameters by simulating a steady state, we also tried to tune the bed and flow parameters by minimizing the RMS difference between observed and a simulated disequilibrium 2009 surface elevation values. The dis-equilibrium state was simulated by forcing the model with a 
Table 3. Details of satellite imagery used, resolution of the velocity map

\begin{tabular}{|c|c|c|c|c|c|}
\hline Glacier name & Satellite imagery & Date of acquisition & Band used & $\begin{array}{l}\text { Resolution of } \\
\text { the imagery } \\
\mathrm{m}\end{array}$ & $\begin{array}{l}\text { Resolution of modelled } \\
\text { velocity field } \\
M\end{array}$ \\
\hline Chhota Shigri & $\begin{array}{l}\text { LC81470382014223LGN00_B8 } \\
\text { LC81470382015258LGN00_B8 }\end{array}$ & $\begin{array}{l}11-8-2014 \\
15-9-2015\end{array}$ & $\begin{array}{l}8 \\
8\end{array}$ & $\begin{array}{l}15 \\
15\end{array}$ & 30 \\
\hline
\end{tabular}

constant balance perturbation of $0.08 \mathrm{~m}$ w.e. $\mathrm{a}^{-1}$ from AD1000-1875 and $b(t)$ for the period 1876-2009. The results obtained from both the kinds of tuning were very similar.

Finally, the adjusted bed along with the adjusted flow parameters was used in subsequent analyses.

\section{RESULTS}

\section{Estimation of bed topography}

The bed topography of Chhota Shigri glacier is shown in Figure 3 . The bed elevation varies from $\sim 4200$ to $4500 \mathrm{~m}$ in the ablation zone and $\sim 5000-5900 \mathrm{~m}$ in the accumulation zone. The bed elevations along three cross sections were validated with GPR measurements (Figs 1, 4). The mean and standard deviation of the uncertainty is $\sim 17$ and $\sim 16 \mathrm{~m}$, respectively. The empirical Cumulative Distribution Function (CDF) of the uncertainty shows that $\sim 74 \%$ of observed ice thickness values were within $\pm 25 \%$ uncertainty in the corresponding modelled ice thickness profiles. A comparison with the cross-sections modelled using Gantayat and others (2014) also shows that the proposed modification using branchlines gives better results.

\section{Estimation of response time}

When the model is run with the adjusted parameters, it takes $\sim 320$ years to produce a steady-state glacier. The steadystate glacier is then subjected to various balance perturbations after 500 years of model run and the subsequent response of the glacier length is shown in Figure 5.

The length response time is defined as the time period required to reach $\left(1 \times 10^{-1}\right)$ of the final response after a stepwise perturbation in climate. The response times were 75 and 67 years for balance perturbations of -0.1 and $-0.2 \mathrm{~m}$ w.e.

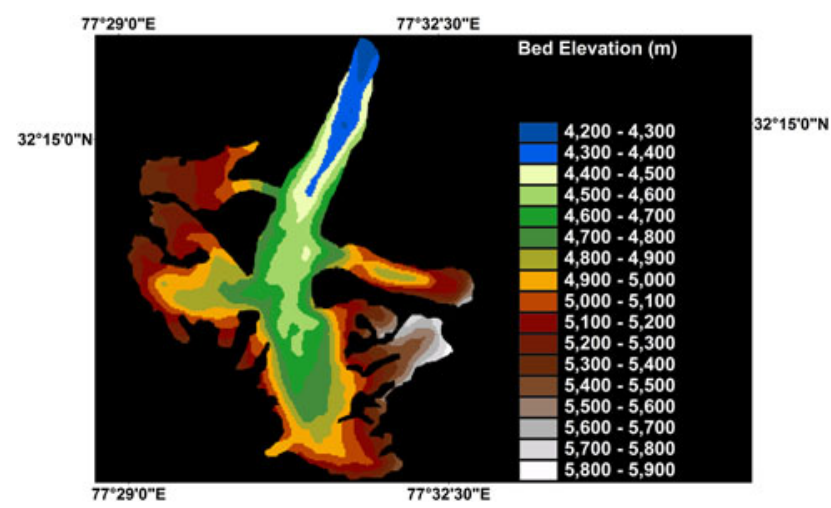

Fig. 3. Modelled bed elevation of Chhota Sigri ranged from $\sim 4200$ to $4300 \mathrm{~m}$ near the snout and $\sim 4400$ to $4450 \mathrm{~m}$ elsewhere along the main trunk. For running the model, the bed elevations along the central flowline was considered as input. $\mathrm{a}^{-1}$, respectively. For positive perturbations of $0.1,0.2 \mathrm{~m} \mathrm{w}$. e. $\mathrm{a}^{-1}$ the response times were 58 and 67 years, respectively. The response times for positive perturbations is slightly less than that for negative perturbations. This is because during retreat the glacier front enters a bed with a relatively smaller slope as compared with that during advance. Similarly, the volume response times for the same set of balance perturbations were 35,36 years for positive perturbations $\left(0.1,0.2 \mathrm{~m}\right.$ w.e. $\left.\mathrm{a}^{-1}\right)$ and 38,40 years for negative perturbations $\left(-0.1,-0.2 \mathrm{~m}\right.$ w.e. $\left.\mathrm{a}^{-1}\right)$. Therefore, the average volume response time leads the average length response time by $\sim 30$ years. The volume response time was also estimated according to Johannesson and others (1989),

$$
\tau_{\mathrm{rvh}}=H \times /\left|\mathrm{B}_{\mathrm{term}}\right|
$$

where $\tau_{\mathrm{rvh}}$ is the volume response time, $H^{*}$ is mean ice thickness and $B_{\text {term }}$ is the specific balance at the terminus. $\tau_{\mathrm{rvh}}$ for Chhota Shigri is $\sim 33$ years.

The glacier carries memory of the past climate for a time period equal to one or two times the response time (Oerlemans, 2001). Therefore, the length response time gives an estimate of how far in time one must run the model to correctly simulate the historical retreat.

\section{Simulation of retreat}

The observed retreat record for Chhota Shigri glacier is rather short (48 years). The large response time of the glacier suggests that the model run should start well before the retreat record. In addition, the mass-balance observations span the period 2002-14, which is also quite small. Therefore, in order to reconstruct the mass-balance history over the past two centuries, we used climate proxies such as temperature and precipitation. We decided to adopt a temperature index like approach (e.g. Zuo and Oerlemans, 1997; Adhikari and Huybrechts, 2009).

For reconstructing the past mass-balance history, annual mean temperature and annual and seasonal accumulated precipitation (1876-2009) from the Meteorological station at Shimla, Himachal Pradesh, were used (Fig. 6a). The major reason behind chosing this station is its long records of temperature and precipitation that span over 134 years, which is also roughly double the average length response time and for a successful retreat simulation, the model run must start from a time that is twice the response time (Oerlemans, 1997; Adhikari and Huybrechts, 2009). The other nearby meteorlogical stations have much shorter records.

Before carrying out further analysis, we chose to fill in the data gaps. For that we estimated the average of five data points prior to the gap and five points later. We assumed that the average of the two averages is a good estimation 

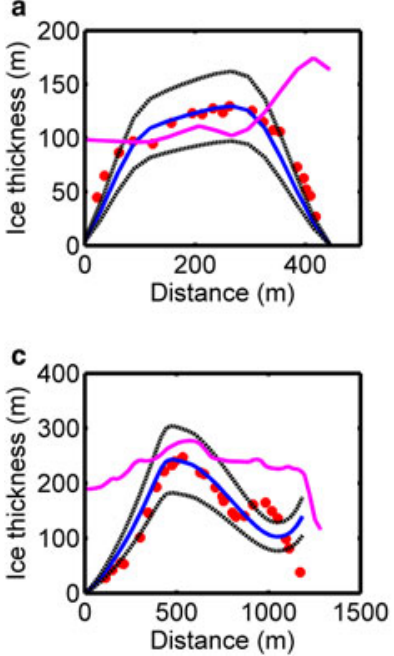

b
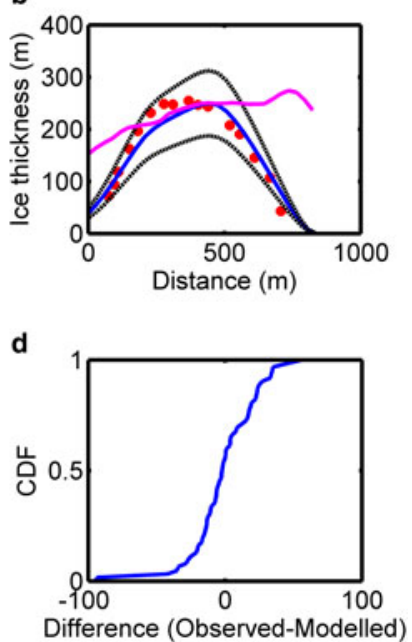

Fig. 4. (a-c) Validation of modelled ice thickness profiles across three cross sections with GPR derived ice thickness (Azam and others, 2012). A model inter-comparison was done with the ice thickness profiles estimated according to Gantayat and others (2014). (d) The empirical cumulative probability distribution function (CDF) of the difference in observed and modelled ice thickness at three cross sections.

for the void. The annual mean temperature showed more correlation with the annual mean mass balance $(R=0.5)$ than that between annual accumulated precipitation and annual mean mass balance $(R=0.4)$. Due to the limited years of mass-balance measurements (2002-14), a proper forcing function had to be established for simulating retreat. Assuming a linear relationship between past balance perturbations, and temperature and precipitation (e.g. Adhikari and Huybrechts, 2009), $b(t)$ is expressed as:

$$
b(t)=\beta\left(\Delta T+\mu_{1}\right)+\theta\left(\Delta P+\mu_{2}\right)
$$

where $\Delta T, \Delta P$ represent temperature and precipitation anomalies by ratio, respectively. Precipitation anomalies by ratio were obtained by dividing annual/seasonal mean precipitation by their corresponding mean for the period 18762009. In our analyses, anomalies were estimated considering 1876-2009 as the base period. $\beta$ and $\theta$ are defined as the mass-balance sensitivity to temperature $\left(\mathrm{m}\right.$ w.e. $\left./{ }^{\circ} \mathrm{C}\right)$ and precipitation sensitivity ( $\mathrm{m}$ w.e. $\mathrm{m}^{-1}$ ) respectively. Their values are unique for each glacier (Adhikari and Huybrechts, 2009); $\mu_{1}$ and $\mu_{2}$ serve as tuning parameters. Their values

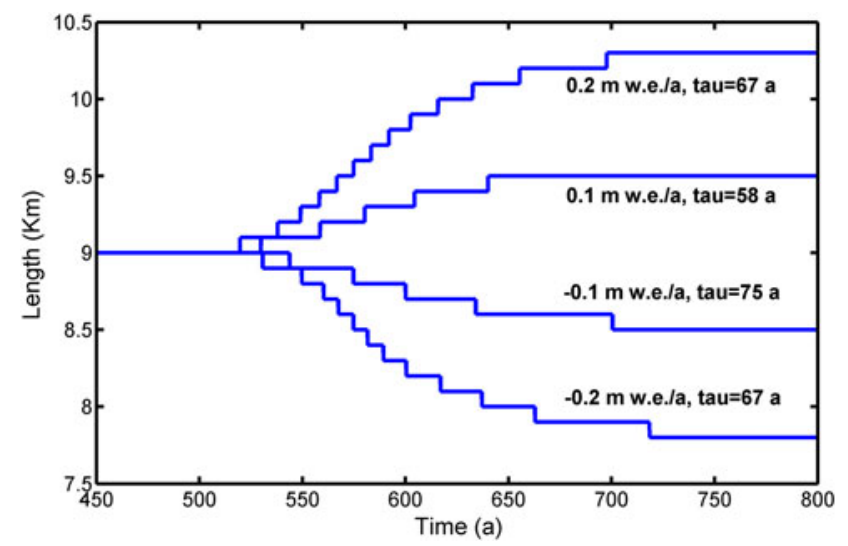

Fig. 5. Response of the steady-state glacier length to different balance perturbations. The response times for positive perturbations are slightly lesser than that for negative perturbations. Average length response time is $\sim 67$ years. are fixed by trial and error so as to get minimum RMS difference between observed and simulated snout positions.

The maximum difference between the observed ELAs as well as the difference between the corresponding annual mass balance was estimated (from 2002 to 2014) from Azam and others (2016). Assuming a vertical lapse rate of $-6.5^{\circ} \mathrm{C} \mathrm{km}^{-1}$, the value of $\beta$ was estimated to be $-0.7 \mathrm{~m}$ w.e. $/{ }^{\circ} \mathrm{C}$. The estimated value of $\beta$ is well within the range of $(-0.52$ to -1$)$, which was estimated by Azam and others (2016) using a degree day model. Interestingly, the value of $-0.7 \mathrm{~m}$ w.e. $/{ }^{\circ} \mathrm{C}$ was estimated at the ELA by Azam and others (2016). The lapse rate is likely to vary seasonally in a complex terrain like the Himalaya. But since the model is forced with mass-balance changes averaged over a year, a constant annual mean value for the lapse rate was assumed, which has also been used previously (e.g. Adhikari and Huybrechts, 2009).

The winter accumulated precipitation recorded at base camp shows a maximum difference of $290 \mathrm{~mm}$ w.e. for the years 2009/10 and 2012/13 (Azam and others, 2016). For estimating $\theta$, the change in annual mean mass balance for the corresponding years was estimated. $\theta$ was estimated to be $0.003 \mathrm{~m}$ w.e. $\mathrm{mm}^{-1}$. In order to get minimum RMS error between observed and simulated lengths, the values of $\mu_{1}$ and $\mu_{2}$ were estimated to be $0.08 \mathrm{~K}$ and 0.07 , respectively.

Our simulation of historic retreat started at the year AD 1000 with zero ice volume as the initial condition and $\delta \mathrm{B}$ was set to zero for both the main stream as well as the tributary. Due to non-availability of meteorological data prior to 1876, we decided to use the period from 1000 to 1875 as a tuning period. From 1876 onwards, the model was forced with $b(t)$ as shown in Figure 6b. A comparison of the simulated and observed surface elevations of the main stream shows good correlation with an RMS difference of $\sim 16 \mathrm{~m}$ (Fig. 7). The simulated and observed surface elevation profiles of the tributary also match quite well with an RMS error of $\sim 15 \mathrm{~m}$ (Fig. 7). The simulated glacier length fluctuations also match with that observed with an RMS error of $\sim 150 \mathrm{~m}$ (Fig. 8). The simulated glacier in 2009 is longer than the observed length by $\sim 100 \mathrm{~m}$. 

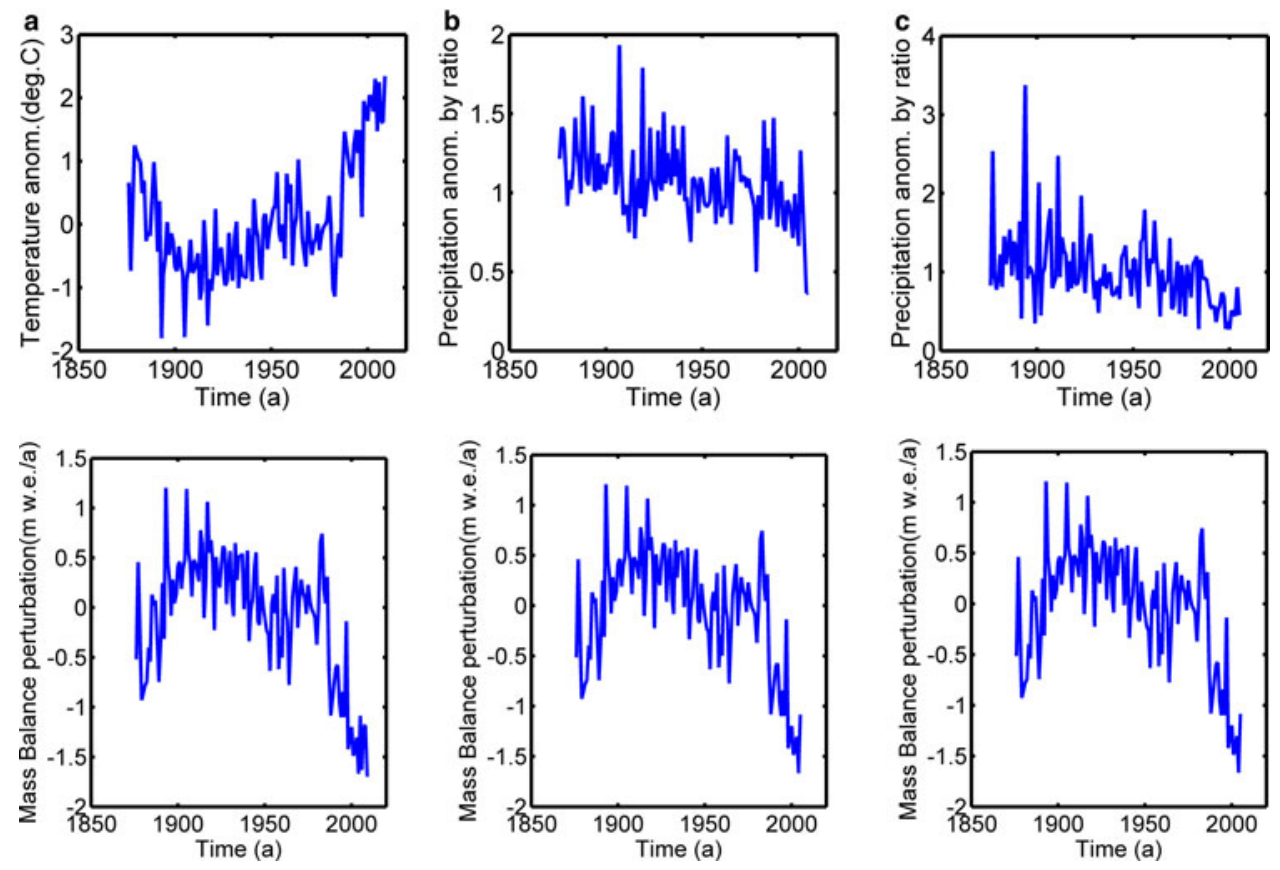

Fig. 6. (a) Meteorological data from Shimla (1876-2009) (a) Annual mean temperature anomalies, (b) Annual mean precipitation anomalies by ratio, (c) Seasonal accumulated precipitation anomalies by ratio. (b) Balance perturbations derived from (a) annual mean temperature anomalies, (b) annual mean temperature and annual mean precipitation anomalies, (c) Annual mean temperature and seasonal mean precipitation anomalies.

\section{DISCUSSIONS}

\section{Characteristics of the simulated 2009 glacier stand}

The simulated driving stress is shown in Figure 9. Except for a small region in the altitude band between $\sim 4900$ and 5000 $\mathrm{m}$, the driving stress is in the range $100-200 \mathrm{KPa}$, which is typically the range in glacier ice. The very high value of the stress $\sim 250 \mathrm{KPa}$ in the altitudinal range $4900-5000 \mathrm{~m}$ is due to the presence of very steep slopes in that part of the glacier bed.

The simulated mean velocity field is also shown in Figure 9. The mean velocity ranged from $\sim 180$ to $10 \mathrm{~m}$ $\mathrm{a}^{-1}$. As ice is lost, the velocity vanishes at the top and glacier's snout. Very high velocity is again found in that altitudinal band of 4900-5000 $\mathrm{m}$ due to very high bed slope. The velocity peaks near the two icefalls at $\sim 6.5$ and $\sim 8 \mathrm{~km}$ from the glacier top. High bed slopes result in less ice
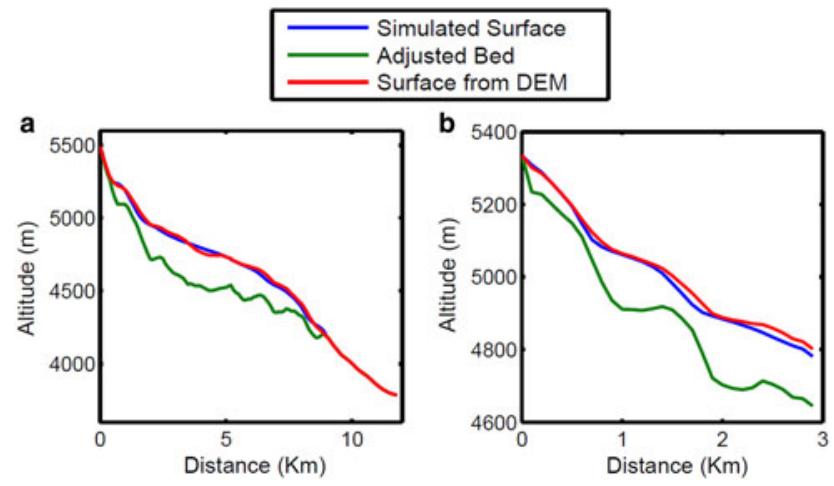

Fig. 7. (a) Comparison of simulated and observed surface elevation of $A$ (main stream). The RMS error is $\sim 16 \mathrm{~m}$. (b) Comparison of simulated and observed surface elevation of B (tributary). The RMS error is $\sim 15 \mathrm{~m}$. The adjusted bed profile has been shown as a green line. thickness, thus increasing the sliding component of the mean velocity (Figs 9, 10). A direct comparison of simulated mean velocity profile and that observed is difficult because the field measurements do not allow a calculation of the mass flux through a glacier cross section averaged over several years, which is what the model simulates (Oerlemans, 1997). However, a comparison of surface velocities for the year 2004/05 (Azam and others, 2012) with mean velocity simulated in 2009 shows that the simulated mean velocity is typically in the range $0.7-1$ times the surface velocities everywhere, except in the altitudinal band of $4900-5000 \mathrm{~m}$.

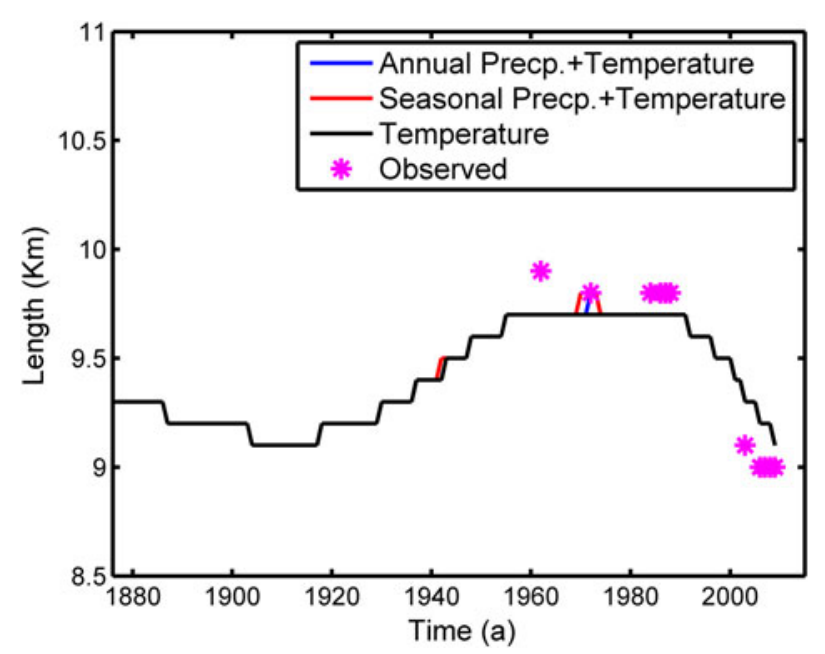

Fig. 8. Glacier length fluctuations due to mass-balance changes derived from climate forcing (Fig. 6b). The ${ }^{\prime * \prime}$ represent the observed front positions. The constant length prior to 1876 is due to the fact that a constant balance perturbation of 0.08 m.w.e. $\mathrm{a}^{-1}$ was used. The RMS difference between observed and simulated glacier lengths is $\sim 150 \mathrm{~m}$. 

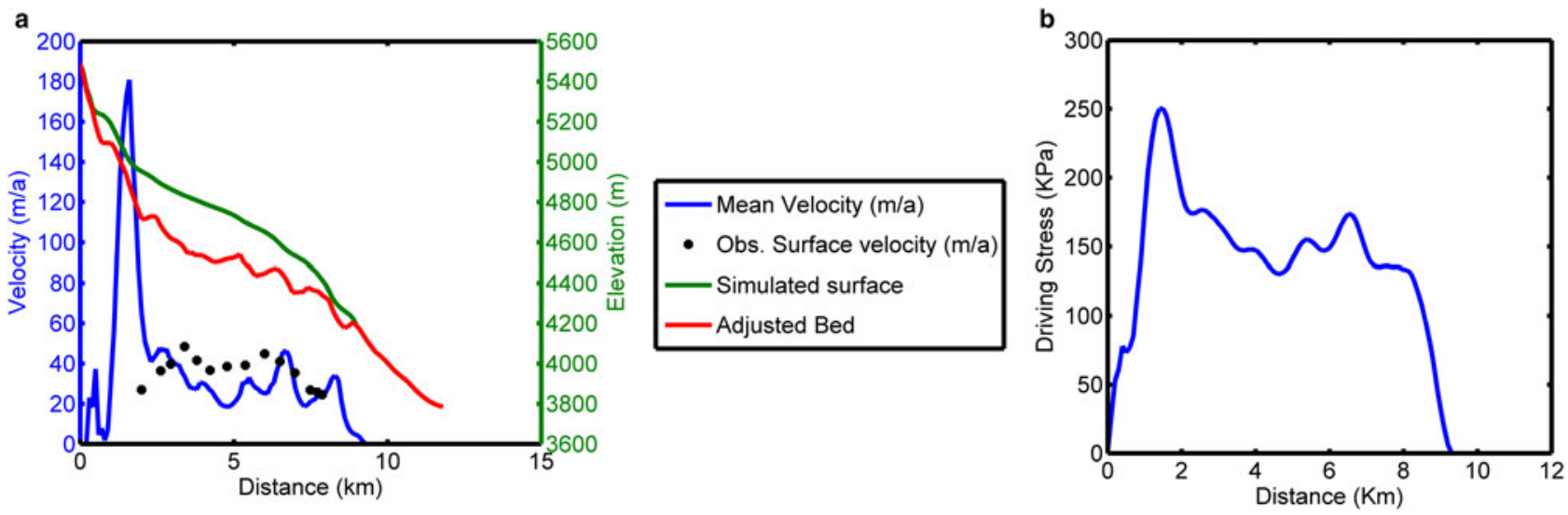

Fig. 9. (a) Simulated mean velocity field during the year 2009. The observed surface velocities during 2004/05 have been represented as **'. (b) Simulated driving stress during the year 2009.

Steep bed slopes indicate presence of icefall in the altitudinal band $\sim 4900-5000$. Here, the model over-estimates the velocity. This is due to the simplistic manner in which $U$ has been formulated in Eqn (2). In reality sliding occurs possibly due to the subglacial lubrication by meltwater that is generally absent in the icefalls. As a result, the effect of higher order stresses on sliding becomes dominant (Adhikari and Marshall, 2013). Another reason could be due that the Chhota Shigri glacier is variously oriented in the accumulation zone (Wagnon and others, 2007), the flowline approximation of the model might not hold true. However, this does not affect the simulation of frontal variation probably because that is mostly governed by dynamics in the ablation area (De Smedt and Pattyn, 2003).

\section{Analysis of past retreat and future projections}

The simulated glacier length increased from 1900 to 1950 and remained constant until 1991 . From 1992 onwards, there has been a continuous retreat; the advance resulted due to a relatively cool period from $\sim 1900$ to 1960 (Figs $6 b, 8)$. The retreat after 1995 seems to be quite rapid when compared with the rate of advance during the period 1900-50. From 1972 to 2006, the modelled retreat was $\sim 700 \mathrm{~m}$, which is quite close to $850 \mathrm{~m}$, a value that was

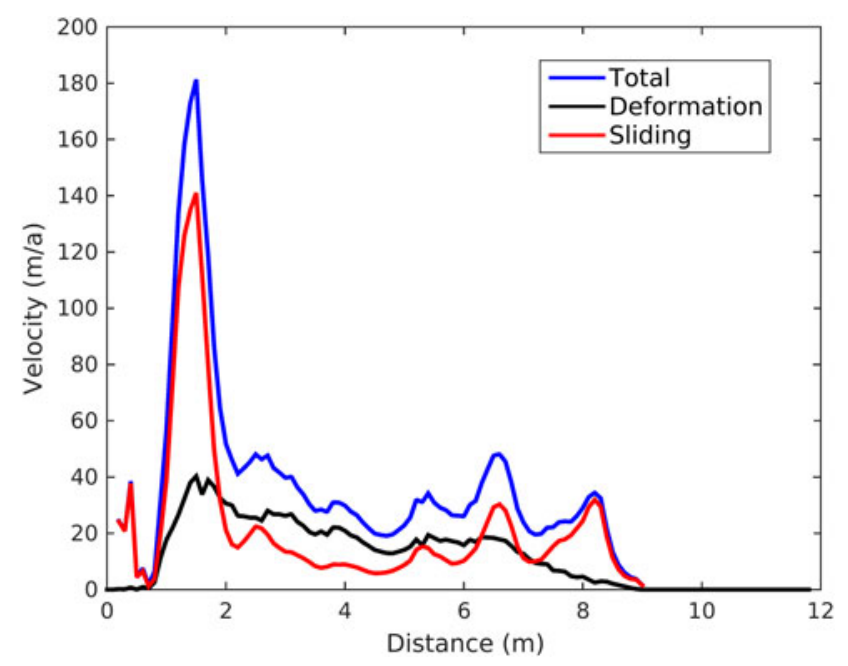

Fig. 10. Simulated mean, deformation and sliding velocity profiles in 2009 . estimated using satellite imagery (Shruti, 2008). The fast retreat can be attributed to two factors: (a) rise in temperature; (b) presence of steep bed below an altitude of $4200 \mathrm{~m}$. The simulation also suggests that from $\sim 1972$ to 1992 , the glacier was in a steady state.

We also tried to determine the dominant climate proxy responsible for retreat. Two experiments were carried out. In the first one, we estimated retreat using only temperature anomalies. In the second experiment, retreat was estimated using both temperature and precipitation anomalies. The results show that precipitation hardly influences the glacier length variations (Fig. 8). Thus, we conclude that historical length variations of Chhota Shigri glacier are mostly influenced by temperature and not precipitation.

After having successfully simulated the historic retreat, four different climatic scenarios under constant precipitation were analysed for predicting the glacier's future evolution. These climatic scenarios have been named as RCP 2.6, RCP 4.5, RCP 6 and RCP 8.6. They predict a temperature rise of $2.36,3.49,3.68$ and $5.51{ }^{\circ} \mathrm{C}$ with respect to 1860 1990 mean, respectively, in the Western Himalaya Karakorm over the next 100 years. Details regarding the scenarios can be inferred from Chaturvedi and others (2014).

The trend of the temperature rise was estimated and was used for model runs after 2009. The results are shown in Figure 11. If the mean temperature for the period 19902009 was assumed to be the mean temperature after 2009,

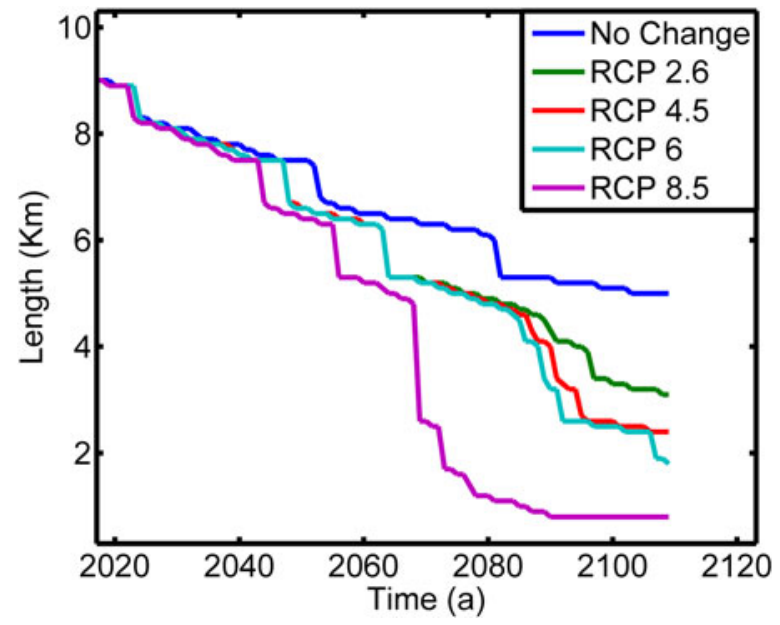

Fig. 11. Glacier length changes under different climatic scenarios. 
the glacier can be expected to retreat by $\sim 4 \mathrm{~km}$ and lose $73 \%$ of 2009 volume by AD 2109. Under RCP 2.6 and 4.5 situations, the glacier is expected to retreat by $\sim 6$ and $6.6 \mathrm{~km}$ as well as lose $92 \%$ and $97 \%$ of its 2009 volume, respectively. Under RCP 6 conditions, the glacier is expected to retreat by $\sim 7 \mathrm{~km}$. Under RCP 8.5 conditions, a steep decrease in the glacier length is to be expected after 2090 because the glacier breaks into fragments.

\section{CONCLUSIONS}

In this study, we present a numerical ice flow model that was used to simulate the historical retreat and future evolution of Chhota Shigri glacier. The simulation was successful with an RMS error of $150 \mathrm{~m}$ between simulated and observed snout positions. This study shows that flowline models can be used to understand the relationship between Himalayan glaciers and climate change. The simulations show that within the next 100 years, the glacier is expected to retreat further by between $\sim 6$ and $6.6 \mathrm{~km}$ for a 2.36 and $3.49 \mathrm{~K}$ rise in temperature, respectively. If the annual mean temperature after 2009 is same as the mean temperature for 1990-2009, the glacier retreats by $\sim 5 \mathrm{~km}$. The glacier ceases to exist by AD 2109 in case of a temperature rise of $5.5 \mathrm{~K}$.

\section{ACKNOWLEDGEMENTS}

We thank Divecha Centre for Climate Change for providing the necessary laboratory resources that were required for this study. We also thank USGS for its free data policy, allowing us to use Landsat 8 Pan imagery.

\section{REFERENCES}

Adhikari S and Huybrechts P (2009) Numerical modelling of historical front variations and the 21st-century evolution of glacier AX010, Nepal Himalaya. Ann. Glaciol., 50(52), 27-34

Adhikari S and Marshall SJ (2011) Improvements to shear-deformational models of glacier dynamics through a longitudinal stress factor. J. Glaciol., 57(206), 1003-1016

Adhikari S and Marshall SJ (2012) Parameterization of lateral drag in flowline models of glacier dynamics. J. Glaciol., 58(212), 1119_ 1132

Adhikari S and Marshall SJ (2013) Influence of high-order mechanics on simulation of glacier response to climate change: insights from Haig glacier, Canadian Rocky Mountains. Cryosphere, 7, 1527 1541 (https://doi.org/10.5194/tc-7-1527-2013)

Azam MF and 10 others (2012) From balance to imbalance: a shift in the dynamic behaviour of Chhota Shigri glacier, western Himalaya, India. J. Glaciol., 58(208), 315-324

Azam MF and 10 others (2016) Meteorological conditions, seasonal and annual mass balances of ChhotaShigri glacier, western Himalaya, India. Ann. Glaciol., 57(71), 328-338

Berthier E and 5 others (2007) Remote sensing estimates of glacier mass balances in the Himachal Pradesh (Western Himalaya, India). Remote Sens. Environ., 108(3), 327-338

Bolch T and 11 others (2012) The state and fate of Himalayan glaciers. Science, 336(6079), 310-314 (doi: 10.1126/science.1215828)

Budd WF, Keage PL and Blundy NA (1979) Empirical studies of ice sliding. J. Glaciol., 23(89), 157-170

Chaturvedi RK, Kulkarni A, Karyakarte Y, Joshi J and Bala G (2014) Glacial mass balance changes in the Karakoram and Himalaya based on CMIP5 multi-model climate projections. Clim. Change, 123(2), 315-328 (doi: 10.1007/s10584-013-1052-5)

De Smedt B and Pattyn F (2003) Numerical modelling of historical front variations and dynamic response of Sofiyskiy glacier, Altai mountains, Russia. Ann. Glaciol., 37, 143-149
Farinotti D and 36 others (2017) How accurate are estimates of glacier ice thickness ? Results from ITMIX, the ice thickness models intercomparison eXperiment. Cryosphere, 11, 949-970 (doi: 10.5194/tc-11-949-2017)

Frey $\mathrm{H}$ and 9 others (2014) Estimating the volume of glaciers in the Himalayan-Karakoram region using different methods. Cryosphere, 8, 2313-2333 (https://doi.org/10.5194/tc-8-23132014)

Gantayat P, Kulkarni AV and Srinivasan J (2014) Estimation of ice thickness using surface velocities and slope: case study at Gangotri glacier, India. J. Glaciol., 60(220), 277-282 (doi: 10.3189/2014JoG13J078)

Glen JW (1955) The creep of polycrystalline ice. Proc. R. Soc. Lond. Ser. A, 228(1175), 519-538 (doi: 10.1098/rspa.1955.0066)

Hutchinson MF (1989) A new procedure for gridding elevation and stream line data with automatic removal of spurious pits. J. Hydrol., 106, 211-232

Johannesson T, Raymond CF and Waddington ED (1989) Time-scale for adjustment of glaciers to changes in mass balance. J. Glaciol., 35(121), 355-369

Kulkarni AV and Karyakarte Y (2014) Observed changes in Himalaya glaciers. Current Sci., 106(2), 237-244

Kulkarni AV and 6 others (2007) Glacial retreat in Himalaya using Indian remote sensing satellite data. Current Sci., 92(1), 69-74

Kulkarni AV, Rathore BP, Singh SK and Bahuguna IM (2011) Understanding changes in Himalayan Cryosphere using remote sensing technique. Int. J. Remote Sens., 32(3), 601-615

Leprince S, Barbot S, Ayoub F and Avouac J (2007) Automatic and precise orthorectification, coregistration and sub pixel correlation of satellite images, application to ground deformation measurements. IEEE Trans. Geosc. Remote Sens., 45(6) (doi: 10.1109/ TGRS.2006.888937)

Linsbauer A, Paul F and Haeberli W (2012) Modeling glacier thickness distribution and bed topography over entire mountain ranges with GlabTop: application of a fast and robust approach. J.Geophys. Res., 117, F03007 (doi: 10.1029/2011JF002313)

Nye JF (1965) The flow of a glacier in a channel of rectangular, elliptical or parabolic cross-section. J. Glaciol., 5(41), 661-690

Oerlemans J (1997) A flow-line model for Nigardsbreen: projection of future glacier length based on dynamic calibration with the historic record. Ann. Glaciol., 24, 382-389

Oerlemans J (2001) Glaciers and climate change. A.A. Balkema Publishers, ISBN 9026518137

Paterson WSB (2010) The physics of glaciers, 4th edn. ButterworthHeinemann, Oxford

Ramanathan AL (2011) Status report on Chhota Shigri glacier (Himachal Pradesh). Himalayan Glaciology Technical Report No. 1. Department of Science and Technology, Ministry of Science and Technology, New Delhi, pp-88p

Schmeits MJ and Oerlemans J (1997) Simulation of the historical variations in length of Unterer Grindelwaldgletscher, Switzerland. J. Glaciol., 43(143), 152-164

Shruti (2008) Study of Glacio-morphological features and deglaciation pattern using field observation data, GIS and remote sensing techniques in the Himachal Himalaya ( $\mathrm{PhD}$ thesis, Jawaharlal Nehru University, New Delhi), p. 128

Smith GD (1978) Numerical solution of partial differential equations: finite difference methods, 2nd edn. Clarendon, Oxford, 304 pp

Stroeven AP (1996) The robustness of one-dimensional, timedependent ice-flow models: a case study from Storglacaieren, Northern Sweden. Geogr. Ann., 78A(2-3), 133-146

Tiwari RK, Gupta RP and Arora MK (2014) Estimation of surface ice velocity of Chhota Shigri glacier using sub-pixel ASTER image correlation. Current Sci., 106(6)

Wagnon P and 10 others (2007) Four years of mass balance on ChhotaShigri glacier, Himachal Pradesh, India, a new benchmark glacier in the western Himalaya. J. Glaciol., 53, 603-611

Zuo Z and Oerlemans J (1997) Numerical modelling of historic front variation and the future behaviour of Pasterze glacier, Austria. Ann. Glaciol., 24, 234-241 